\title{
LITHUANIAN UNIVERSITY STUDENTS' MOTIVATION TO STUDY ENGLISH
}

\author{
Aurelija Daukšaitè-Kolpakovienè \\ Vytautas Magnus University, Lithuania
}

\begin{abstract}
Lithuanian university students' motivation to study English as an obligatory study subject seems to be not researched. This is the reason why this study attempts to fill in the existing gap by aiming to learn how motivated Lithuanian students are to learn English at a liberal arts university in which English (as a foreign language) is obligatory to study. 61 upperintermediate level students at Vytautas Magnus University (VMU) in Kaunas (Lithuania) were involved in the study and filled in an anonymous online questionnaire to reflect on their motivation to study English. The questionnaire involved statements on demographic information and 21 statements on different types of motivation. In addition, the research participants needed to explain in writing why they chose specific statements (all of which started with I study English because ...). Thus, it was a quantitative and qualitative study, since qualitative data is lacking in various previous research on student motivation. The findings show that the Lithuanian university students are mostly instrumentally oriented. They hardly see English as an obligatory subject, even though it is, and intend to use it mainly as a tool to achieve various goals in the future, for instance, while travelling, communicating and working. Therefore, English teachers should place the learning content in these contexts to increase student motivation to study. This research may also have implications for the teaching of other obligatory non-speciality subjects at a liberal arts university, such as VMU.
\end{abstract}

Keywords: English as a foreign language, instrumental motivation, motivation to study English, university students, VMU.

\section{Introduction}

At Vytautas Magnus University (VMU) in Kaunas, Lithuania, English is an obligatory study subject to all first cycle study programme students, so they cannot choose not to study it. Usually the students have to gain advanced knowledge of English (C1 level according to the CEFR) during the first two years of their studies. This research aims to learn how motivated Lithuanian students at VMU are to study English at upper-intermediate level. It is hoped that the exploration of motivation will help to 
understand what characterises the students and their attitudes, experiences of learning English and expectations, since it is an obligatory study subject, just like some others not necessarily directly related to the students' field of study but meant to provide with universal liberal arts education at VMU.

Gardner (2010, p. 8) states that there is no one simple definition of what it is, as different researchers provide numerous definitions. According to Harmer (2006, p. 51), "motivation is some kind of internal drive which pushes someone to do things in order to achieve something". In a similar manner, motivation can be seen as a passion to achieve one's goals or a reason to do something (Oroujlou \& Vahedi, 2011, pp. 995-997). Most frequently two types of motivation are distinguished: intrinsic motivation that "comes from within the individual" and extrinsic motivation which "is caused by any number of outside factors" (Harmer, 2006, p. 51). That is, intrinsic motivation comes from the individual himself/ herself, while extrinsic motivation is influenced by some other, usually outside, source. Extrinsic goals can be either short-term or long-term: the former ones usually are related to grades, prizes, competitions, similar awards (Oletic \& Ilic, 2014, p. 26), money and even positive feedback of some types (Pan, 2010, p. 151), while the latter ones involve a longer period of time and are related to opportunities to find a better job in the future, climbing up the social ladder, etc. (Oletic \& Ilic, 2014, p. 26). Nevertheless, in order to be successful at something, intrinsic motivation is said to be more important (Harmer, 2006, p. 51) and related to success in the long term, while extrinsic motivation is associated with short-term success (Pan, 2010, p. 151).

There are several other types of motivation distinguished. Gardner (2010), Wang (2008) and Kormos, Csizer, Menyhart and Török (2008) research integrative motivation which in a foreign language learning context means that a student wants to become like people who speak, for instance, English or likes their culture. Another type is instrumental motivation, which means that a student who studies English does it for a future job/career, higher salary of the job, travelling, getting good grades or simply in order to pass a course or an exam (Kormos et al., 2008, p. 72; Wang, 2008, pp. 633-634). It is important to emphasise that travelling, for example, can be either integrative or instrumental, because it depends on the actual purpose of travelling (Gardner, 2010, p. 16). Furthermore, achievement motivation is related to planning and effort to achieve goals and a wish for excellence in general. That is, a variety of the mentioned types reflects on the need to identify specific motivation accurately. The next section discusses previous research on motivation in the context of foreign language learning, English in particular. 


\section{Previous Research on Motivation to Learn English}

A great number of studies on student motivation to study English have been carried out in other countries. For example, a Hungarian study revealed that external motivation was the drive in English studies, so a lack of such motivation did not help students to improve and did not encourage putting more effort into learning (Kormos et al., 2008, p. 65). Moreover, Gonzalez Ardeo's (2016) research findings in Spain indicated that intrinsic student motivation depended on gender, while instrumental motivation depended on age. Furthermore, Altun's (2017) research in Turkey showed that students' instrumental motivation differed greatly depending on a study programme, since their job prospects depended or did not depend on their English skills (Altun, 2017, p. 67). In a different study, Ekiz and Kulmetov (2016) learnt that first-year upper-intermediate students in a Turkish university were motivated to learn English when their parents encouraged them and were also more motivated while learning with friends. The research participants were also motivated by the teacher who was almost a native speaker and explained why the activity was needed and how it would be related to certain real life situations (Ekiz \& Kulmetov, 2016, p. 28).

Wang (2016) researched motivation in a university in China, and the results showed that learning English was mostly certificate-oriented, as future prospects and opportunities for a prestigious job often depended on it. This means that the students were extrinsically motivated and their motivation was also instrumental. Nevertheless, Wang's (2008) research emphasises cultural differences while discussing motivation for learning English. For instance, examinations motivate Chinese students greatly but travelling abroad in the future does not, while in Tony Lai's (2013) study, Taiwanese undergraduate students studied English for travelling and were both instrumentally and integratively motivated.

In short, there have been numerous studies on university students' motivation to learn English. They differ not only in their participants (nationality, year of study, study programmes, etc.) and design but also in terms of results. As discussed above, motivation to study English might depend on the country or culture, but it can also be related to individual needs and desires. However, Lithuanian students' motivation to study English as an obligatory study subject at a liberal arts university has not been researched yet.

\section{Method}

The present study investigates how motivated Lithuanian students are to learn English. At VMU, English is an obligatory study subject during the first two years in bachelor studies in all study programmes. A1-B2 level 
courses are general English courses. Whether students need to study these depends on their enrolment grades, international tests and VMU placement test of English. However, students must reach levels C1-C2 of English. Thus, if the enrolment results are low, such students study English longer till they reach level B2 and only then need to take courses of English for specific purposes (ESP) at C1-C2 levels.

An online questionnaire which consisted of both qualitative and quantitative statements was administered to 61 VMU students who were studying English at B2 level in a distance mode in the fall semester of 2020. They had been informed about the study during one of their classes but participated in it not during their class time. The questionnaire was of two parts: one on demographic data and the other one on 21 statements starting with I study English because... They were the following: 1. it is an obligatory subject at my university/ study programme; 2. my parents/ teachers force/ make me to; 3. getting a good grade will increase my grade average significantly; 4. it makes me feel happy and enjoy it; 5. I am interested in the subject; 6. I like the materials/ books/ tasks/ online tools, etc. used to teach it are interesting; 7. I like learning new things/ languages; 8. I like the English language in general; 9. it is challenging; 10. I would like to speak like a native speaker of English; 11. I would like to speak English fluently; 12 . I would like to live abroad; 13. I would like to speak English as well as other students in my university/ study programme/ study group; 14. I like the cultures of English speaking countries; 15. I like songs/films, etc. in English; 16. knowing it I will be able to express myself in a foreign language; 17. I want to pass my final exam with a good grade; 18. I will need it/ for my future job/ career; 19. Knowing it will allow me to read literature/ materials for other courses in English; 20. It will help me to make foreign friends/ communicate with them; 21. I need it for travelling.

The research participants were able to choose as many statements as they needed if the statements could be applied to their motivation to study English. Statements 1-3 were on extrinsic motivation, 4-9 on intrinsic motivation, 10-13 on achievement motivation, 14-16 on integrative motivation, and 17-21 on instrumental motivation. It is also important to emphasise that sometimes certain statements could be assigned to different types of motivation. For instance, Statement 18 may also reflect on extrinsic motivation, while Statement 21 can also refer to integrative motivation (Gardner, 2010, p. 16). Consequently, the respondents were provided with a box to explain their choices in greater detail, since it had been noticed that in numerous research studies on student motivation the collected data usually was not interpreted by their participants. It was hoped that the explanations would provide valuable insight into student motivation to 
study English and help to identify it more precisely. All the collected data was analysed using Microsoft Excel.

Out of the total of 61 respondents, $72.13 \%$ were female students, while $27.87 \%$ were male students. All the respondents were bachelor's degree students: $83.67 \%$ of them were in their first year of studies, in other words, they were freshmen; $14.8 \%$ of the participants were in their second; and $1.6 \%$ in their third study year.

\section{Results}

As the results show, there is no one particular reason that motivates but rather a variety of them. The most frequently chosen statements or reasons are given in Table 1.

Table 1. The most frequently chosen statements

\begin{tabular}{|c|c|l|}
\hline Statement number & $\begin{array}{l}\text { Number of students who } \\
\text { chose it (out of 61) }\end{array}$ & Type of motivation \\
\hline 15 & 51 & Integrative \\
\hline 11 & 48 & Achievement \\
\hline 21 & 45 & Instrumental \\
\hline 20 & 40 & Instrumental \\
\hline 8 & 37 & Intrinsic \\
\hline 16 & 35 & Integrative \\
\hline 18 & 35 & Instrumental \\
\hline
\end{tabular}

It shows that the research participants are mostly instrumentally and integratively oriented, but achievement and intrinsic motivation is also important. The explanations provided by the research participants might reveal a bigger picture about their motivation, so descriptive analysis was used to overview the comments made by the research participants.

\section{Discussion}

The comments are discussed based on the type of motivation they explain. In addition, in order to refer to specific participants without giving their names, certain abbreviations or rather codes are used, for example, "R1." stands for "research participant number 1."

Since three out of seven most frequently chosen statements show instrumental orientation, they are discussed first. It appears that it is important for the students to be able to use English as an instrument to achieve 
different goals in the future. One of such goals is to use English while travelling (Statement 21) either to English speaking countries or other countries in general for pleasure or for studies. In addition to travelling, making foreign friends and/ or communication with them (Statement 20) motivates to study English, because the English language serves as a tool for such communication. Moreover, knowing English helps to create closer/ better/ more sincere/ more fulfilling relationships with foreigners. This can be applied to both relationships in the real world and those in the virtual environment or social networks.

One more practical reason to study English is a likely need of it in one's future job or career (Statement 18). As the research participants are university students from different faculties, their given explanations reveal the participants' future plans and how they are actually going to use English after they graduate. The analysed comments suggest that English will be needed in such specialities as follows: translation, politics, business, education and others, but a substantial part of the respondents reflects on the need of English in all occupations and fields of work, too.

Integrative motivation, which is related to a wish to be like other people who speak English or appreciation of the English culture, is also important to the research participants. However, having chosen Statement 16, the respondents provided the explanations that in fact express either intrinsic (e. g. R29., R22.) or instrumental (R20., R21., R58.) motivation, not integrative motivation as it was thought before the research. Nevertheless, those who have chosen Statement 15 do provide reasons to study English that actually reveal integrative motivation. These reasons are mostly related to popular culture, since the research participants like watching films, TV shows, TV series and videos in English, listening to music in English or appreciate the English culture in general, because there is much of it everywhere.

Achievement motivation is related to one's personal goals and excellence. As Singh (2011, p. 165) states, "[a]chievement motivation is expectancy of finding satisfaction in mastery of difficult and challenging performances where as in the field of education in particular it stands for the pursuit of excellence". Indeed, some research participants indicated it, e. g. R.6, R.11, R.12, R.17, R.34, R.36, R.49, etc., since they explained their wish to learn to speak English fluently (Statement 11) as being related to gaining self-confidence, achieving excellence in English, expressing themselves and their feelings, being understood or overcoming their fear or complex to speak in English. However, quite many other explanations are in fact related to instrumental rather than achievement motivation, for instance, related to travelling (R. 3, R.61), communication (R.8, R.14, R.20, R.21, R.48) and finding a job where the English language would be needed 
(R.39, R.40). This only proves once again how strongly the research participants are instrumentally motivated and oriented.

Since internal motivation refers to someone's internal wish to learn English, it is pleasant to see that the research participants like the English language in general (Statement 8) and study it not because the subject is an obligatory one in their university study programmes. The participants' explanations reveal that English is a beautiful language and they like the way it sounds. Even though the statement itself is on intrinsic motivation and the explanations provided by the research participants are in line, in fact instrumental motivation is present in some explanations, too (e. $\mathrm{g}$. R.12 who reflects on English being a tool for communication).

Of course, some limitations of the research could not be avoided, since the research included three randomly chosen English classes of upper-intermediate students rather than equal numbers of students to represent different faculties at VMU.

\section{Conclusions}

Knowing students' motivation could help teachers to make their teaching more effective despite the field of students' study at university and have a greater effect on the students' overall performance. As the research shows, Lithuanian university students are mostly instrumentally oriented, so their university teachers of English should include more of the content that would clearly show a strong connection to the real world and how the students will be able to use their knowledge gained in the English language classes in the future outside the classroom. Since Lithuanian university students are motivated to use their English skills while travelling, communicating or working, real life situations including these contexts are essential for their motivation in the classroom of general English at B2 level. However, usually future employment situations and skills are focussed on only later by ESP teachers when students study level C1-C2 courses of English at VMU. Thus, it is evident that teachers of general English at lower levels should do this as well, since Lithuanian students start thinking about their future careers a lot earlier than they start studying ESP courses.

At the same time, the research may have implications for the teaching of other obligatory non-speciality subjects at a liberal arts university, such as VMU. If students are instrumentally oriented, their teachers should demonstrate how specific obligatory subjects will be useful to the students in the future in order to increase their motivation to study. 


\section{References}

Altun, S. (2017). Do the Students from Different Majors Differ in Motivation Type Towards Learning English as a Foreign Language? International Journal of Language Academy, 5 (5 CUELT Special Issue), 67-77. http://dx.doi.org/10.18033/ijla.3651

Ekiz, S., \& Kulmetov, Z. (2016). The Factors Affecting Learners' Motivation in English Language Education. Journal of Foreign Language Education and Technology, 1(1), 18-38. Retrieved from: http://jflet.com/jflet/index.php/jflet/article/view/12/157

Gardner, R. C. (2010). Motivation and Second Language Acquisition. New York: Peter Lang.

Gonzalez Ardeo, J. M. (2016). Learning Motivation and Strategies of ESP University Students. Revista de Lenguas para Fines Especificos, 22(1), 141-169. http://dx.doi. org/10.20420/rlfe.2016.308

Harmer, J. (2006). The Practice of English Language Teaching. Vol. 8. Harlow: Longman.

Kormos, J., Csizer, K., Menyhart, A., \& Török, D. (2008). Great Expectations. The Motivational Profile of Hungarian English Language Students. Arts \& Humanities in Higher Education, 7(1), 65-82. https://doi.org/10.1177/1474022207084884

Oletic, A., \& Ilic, N. (2014). Intrinsic and Extrinsic Motivation for Learning English as a Foreign Language. ELTA Journal, 2(2), 23-38. Retrieved from: http://eltajournal. org.rs/wp-content/uploads/2014/12/V-Intrinsic-and-Extrinsic-Motivation-for-LearningEnglish-as-a-Foreign-Language-by-Aleksandra-Oleti\%C4\%87-and-Nina-Ili\%C4\%87.pdf

Oroujlou, N., \& Vahedi, M. (2011). Motivation, Attitude, and Language Learning. Procedia - Social and Behavioral Sciences, 29, 994-1000. https://doi.org/10.1016/j.sbspro. 2011.11.333

Pan, G. (2010). A Survey on English Learning Motivation of Students in Qingdao Agricultural University. Journal of Language Teaching and Research, 1(2), 151-156. https://doi:10.4304/jltr.1.2.151-156

Singh, K. (2011) Study of Achievement Motivation in Relation to Academic Achievement of Students. International Journal of Educational Planning \& Administration, 1(2), 161-171. Retrieved from: https://www.ripublication.com/ijepa/ijepav1n2_8.pdf

Tony Lai, H.-Y. (2013). The Motivation of Learners of English as a Foreign Language Revised. International Education Studies, 6(10), 90-101. http://dx.doi.org/10.5539/ies. v6n10p90

Wang, D. (2016). A Study on Students' Instrumental Motivation for English Learning in Chinese Universities. Proceedings on the 2016 International Conference on Education, E-learning and Management Technology, 140-143. https://doi.org/10.2991/ iceemt-16.2016.27

Wang, F. (2008). Motivation and English Achievement: An Exploratory and Confirmatory Factor Analysis of a New Measure for Chinese Students of English Learning. North American Journal of Psychology, 10(3), 633-646. Retrieved from: http://selfdeterminationtheory.org/SDT/documents/2008_WangFX_NAJP.pdf 